\title{
Research on the Core Advantages of Jing dong Mall
}

\author{
Xiaoqing $\mathrm{Bi}^{1, \text { a }}$, Dong Zhang ${ }^{1, \mathrm{~b}}$ \\ ${ }^{1}$ School of Tianjin University of technology, Tianjin 300384, China; \\ ${ }^{1}$ School of Tianjin University of technology, Tianjin 300384, China; \\ abi_xiaoqing@163.com, bzhangdong11090132@163.com,
}

Keywords: E-commerce Jing dong Mall Operating income Self-logistics model

\begin{abstract}
In recent years, with the pace of development of domestic e-commerce has gradually accelerated, the pillar of logistics has become increasingly prominent, e-commerce enterprises to logistics services as a key factor in the success or failure of the company, thus driving the logistics theory research boom. In the e-commerce environment the B2C enterprise self-built logistics research, especially by the academic community of widespread concern. In this paper, the most typical business - Jing dong Mall, for example, the first analysis of the current e-commerce business income, on the basis of the depth of mining Jing dong Mall operating rate to maintain industry-leading internal reasons, and through the Jing dong self-logistics model Competitive research, study the domestic electricity business enterprises in the logistics development of new problems, put forward for reference advice and opinions.
\end{abstract}

\section{Introduction}

E-commerce is a significant sign of modern new forms of economy: it achieves rapid processing and delivery of information, breaking the time and geographical constraints. But , also changed the traditional business model, a profound impact on the development of society as a whole. With the rapid development of e-commerce and market economy, as well as the increasing demand for diversification of customer service, the uncertainty of the market demand of electricity providers has greatly increased, which has brought serious challenges to major commercial enterprises. Jing dong formally entered the field of e-commerce in 2004, adhere to the pure e-commerce mode of operation, Jing dong 2015 annual total transactions reached 462.7 billion yuan (about 71.4 billion US dollars), net income of 1813 billion yuan (about 28 billion US dollars) Sales-oriented B2C site transaction size, Jing dong 56.3\% market share ahead, and in the B2C shopping site overall transaction size to occupy 22.8\% market share, Jing dong 2015 earnings report, Jing dong 2015 annual core transactions total 446.5 billion yuan, an increase of $84 \%$. Among them, the core of home appliances 3C business, 2015 annual total turnover of 228.9 billion yuan, up 65\% over last year. Total trading volume in 2014 was RMB14.08 billion, an increase of 78\% from 2013, and Qiang dong Liu also proposed the "three trillion Jing dong" and "national Jing dong" two major vision. Some people think that the development of Jing dong in recent years is too radical, and some people think that the rapid development of Jing dong behind its logistics in its help refueling. But in the end whether the logistics in the Jing dong turnover soaring to provide thrust, how much of this thrust in the end but no one has been measured ${ }^{[1]}$. This article is to use quantitative analysis methods to explain the logistics in the Jing dong sales growth in the end of the importance of how much logistics can be regarded as a core competitiveness of Jing dong. 


\section{Electric business enterprise operating income}

Table.1 Comparison of the four major business enterprises

\begin{tabular}{|c|c|c|c|c|}
\hline & 2012 & 2013 & 2014 & 2015 \\
\hline Jing dong (Unit: RMB million) & 41381 & 69300 & 115000 & 204700 \\
\hline Revenue growth (100\%) & $95.85 \%$ & $67.47 \%$ & $65.95 \%$ & $78 \%$ \\
\hline Dang dang (unit: million yuan) & 5190 & 6325 & 14200 & 8856 \\
\hline Revenue growth (100\%) & $27.07 \%$ & $21.87 \%$ & $24.51 \%$ & $-37.63 \%$ \\
\hline Alibaba (Unit: RMB million) & 25664 & 49100 & 70800 & 76204 \\
\hline Revenue growth (100\%) & $73.71 \%$ & $91.32 \%$ & $44.20 \%$ & $7.63 \%$ \\
\hline Su ning (Unit: RMB million) & 98357 & 105434 & 108900 & 135600 \\
\hline Revenue growth (100\%) & $4.76 \%$ & $7.20 \%$ & $3.29 \%$ & $24.52 \%$ \\
\hline
\end{tabular}

It can be seen from the figure Jing dong Mall in recent years, the growth rate of business income in the same enterprise has been far ahead, and Jing dong Mall has been leading the internal reason is it? This article will attempt to analyze the reasons for the leading revenue in Jing dong from the perspective of customer satisfaction ${ }^{[2]}$.

\section{Comparative Analysis of the Satisfaction of Electric}

3.1 In order to analyze the level of satisfaction and the specific impact of the customer's satisfaction with the evaluation of the level of electricity, this article first days cat, Jing dong, Amazon, Dang dang, Su ning several companies to compare the customer satisfaction, In order to assess Jing dong in terms of satisfaction with the evaluation of whether there is a competitive advantage and which is to bring it a competitive advantage. The following data collection is in the form of a questionnaire survey, we used 300 questionnaires, a total of 280 copies. The results of the data collation as follows Table 2:

\begin{tabular}{|c|c|c|c|c|c|c|}
\hline & Tian mao & Jing dong & Amazon & Dang dang & Su ning & Weights \\
\hline $\begin{array}{c}\text { Product diversity and } \\
\text { personalization }\end{array}$ & 0.67 & 0.55 & 0.47 & 0.5 & 0.47 & $15.2 \%$ \\
\hline product quality & 0.6 & 0.77 & 0.7 & 0.63 & 0.63 & $17.6 \%$ \\
\hline brand effect & 0.59 & 0.65 & 0.56 & 0.45 & 0.5 & $14.4 \%$ \\
\hline Logistics Services & 0.58 & 0.86 & 0.67 & 0.56 & 0.63 & $18 \%$ \\
\hline $\begin{array}{c}\text { Communication } \\
\text { efficiency }\end{array}$ & 0.76 & 0.66 & 0.55 & 0.52 & 0.71 & $16.8 \%$ \\
\hline Customer trust & 0.74 & 0.85 & 0.67 & 0.6 & 0.68 & $18 \%$ \\
\hline Total score & 3.94 & 4.34 & 3.62 & 3.26 & 3.62 & $100 \%$ \\
\hline
\end{tabular}

From the table can be seen Jing dong customer satisfaction the highest, followed by the day cat, Amazon and Su ning, Dang dang the worst. We can see that Jing dong in the e-commerce market competition is a clear competitive advantage, and Jing dong logistics services and customer trust in both the most prominent performance.

\subsection{Peak final theorem analysis online shopping links}

According to the above conclusions Jing dong in customer satisfaction is the highest, then in a series of online shopping in the online shopping links in the end which is the most attractive customers to meet customer needs. We can use the peak law to explain the good relationship between the user and the electricity business to establish a good relationship between the reasons, so we try to use the final law to assess the user online shopping through the various processes or functions, in order to final evaluation of the user online shopping The user experience ${ }^{[3]}$. Using the 
classic usability test method of the task test script, so that users involved in the test in accordance with the pre-designed process to complete the user's use or experience of the product, and after each important process to assess the user's score on the link, and ultimately can Get each user evaluation of all aspects of online shopping. The basic steps of general usability testing can be divided into preparing test cases, recruiting testers, preparing the test environment, organizing observation, and testing. But how will more than one user evaluation score integration to get a final user experience online shopping curve? A simple average can be used to obtain an average ${ }^{[4]}$. Taking into account the peak of the experience may appear in the function we do not want to test, which no longer meet the results of the user research. At the same time, the importance of each user on the various aspects of online shopping is not the same, so we can not ignore the importance of differences between different users, on the basis of this analysis, through the importance score to correct the experience score curve, and ultimately access to users Experience scores are as follows:

(1) $\operatorname{Exp}=$ Peak+End

(2) $\mathrm{J}=\max \{\mathrm{i}|\mathrm{xi} * \mathrm{yi}|\}$

(3) $P e a k=x j * y j$

(4) End $=x$ edn * y edn.

The user experience score is equal to the peak of the experience score and the final experience scores are added. $\mathrm{X}$ represents the experience score, and $\mathrm{Y}$ represents the importance score, so each score is the experience score multiplied by its importance score. And then remove the absolute value of the largest number

Which is the peak of the experience, the same, the final score is equal to the end of the experience score multiplied by its importance score.

The following we will use the final analysis of the finale of the five electrical business in the whole part of the online shopping in which part of the customer satisfaction greatly increased, as follows:
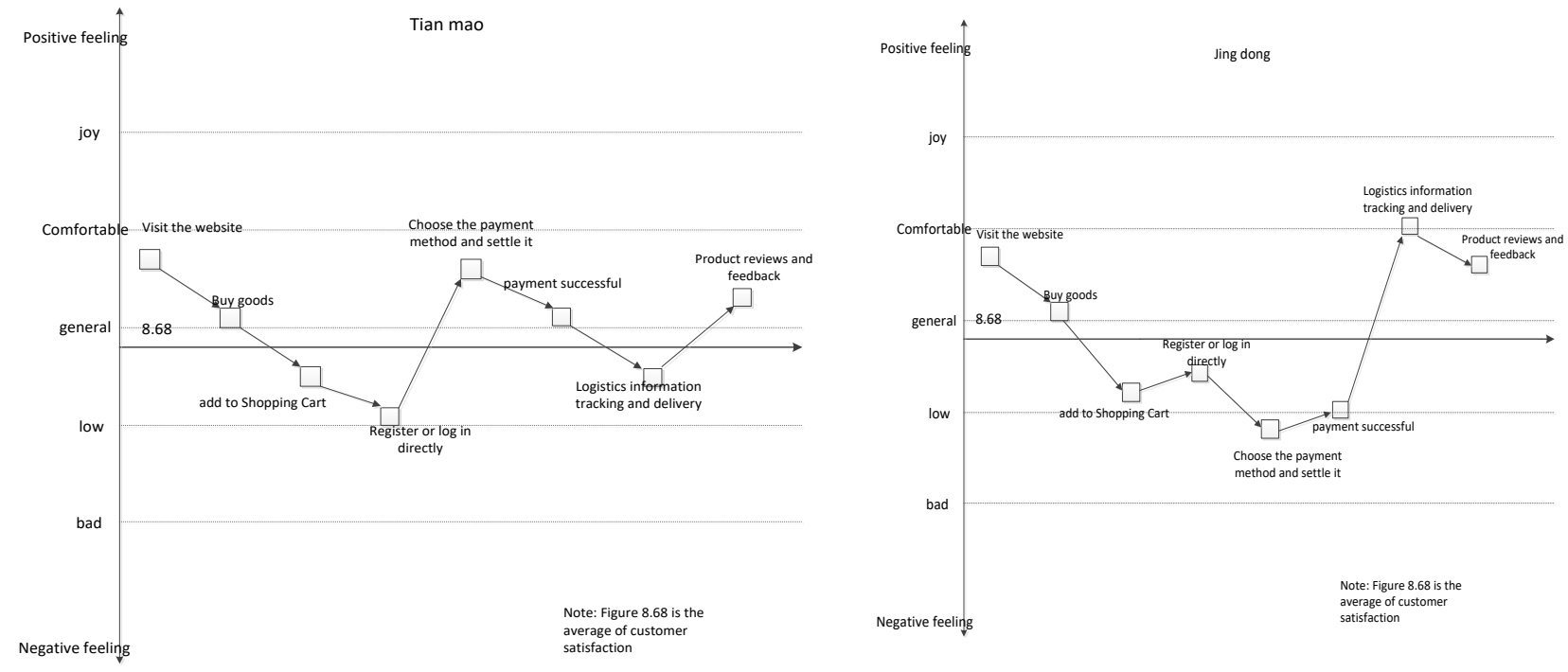


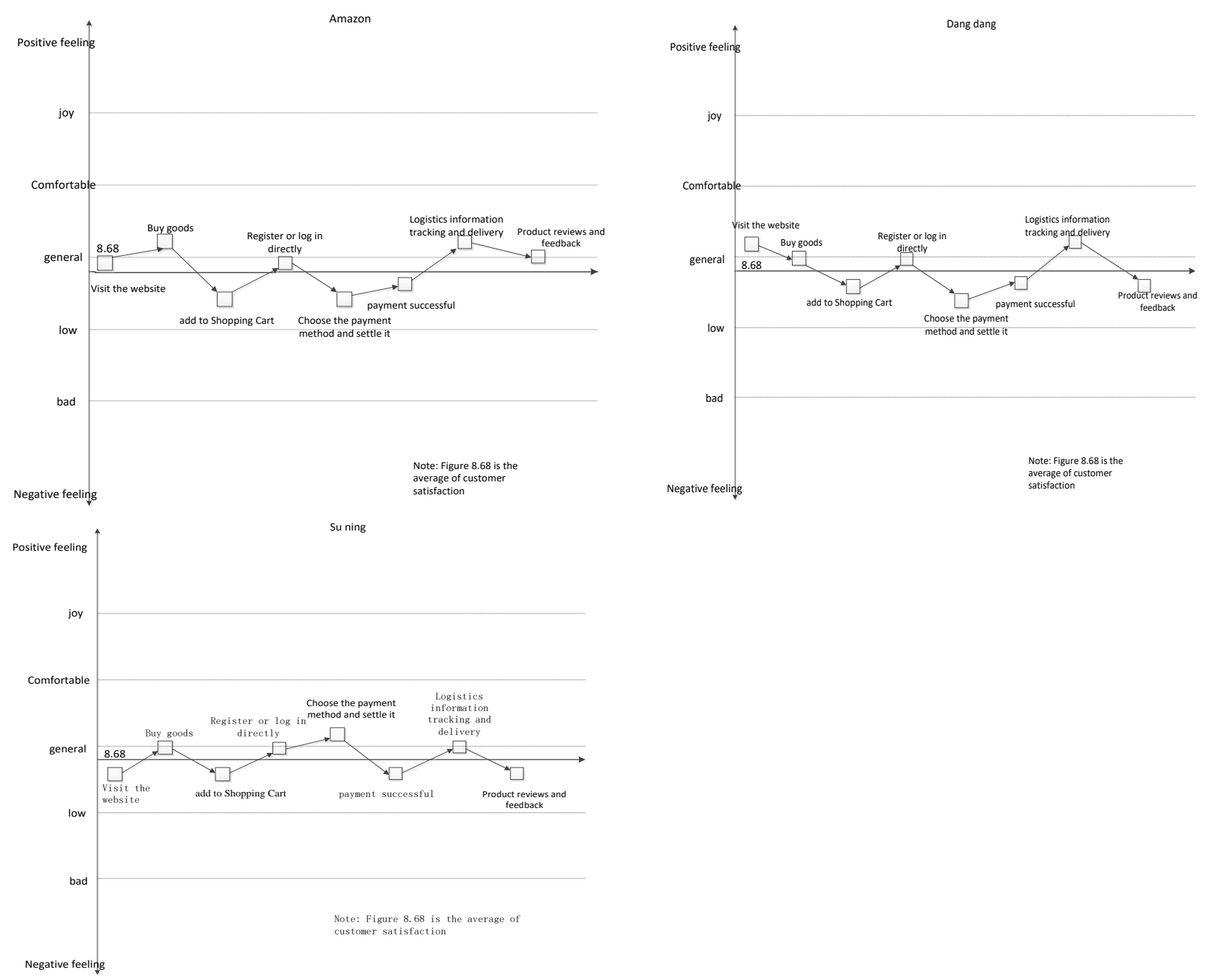

Figure 1 Customer Satisfaction Analysis

From the above figure can be clearly seen in the entire online shopping in the Jing dong logistics information tracking and peak arrival of the highest, product evaluation and feedback for the end and the score is also high, have reached a comfortable effect, the other electric business Performance is more general.

We through the five e-commerce company's horizontal and vertical contrast can be seen Jing dong logistics services throughout the online shopping links played a great role in enhancing the user's overall level of customer experience in Jing dong Jing dong in the e-commerce market Competition is a weapon, but also the core strength of Jing dong.

\subsection{Jing dong logistics advantages of the source and lamb compared}

Jing dong logistics and more to self-logistics, and Lynx is completely outsourced to third-party logistics company, Jing dong in logistics services is significantly better than the general third-party outsourcing logistics, then it's where the advantages of it, the following we Through the analysis of the two delivery process to compare the logistics advantage in the end Jing dong where. 
Table.3 Comparison of logistics advantages

\begin{tabular}{|c|c|c|}
\hline $\begin{array}{c}\text { Tian mao } \\
\text { logistics process }\end{array}$ & $\begin{array}{c}\text { Jing dong logistics } \\
\text { process }\end{array}$ & \\
\hline$\checkmark$ & $\checkmark$ & Place an order \\
\hline$\checkmark$ & $\checkmark$ & The system confirms the order \\
\hline$\checkmark$ & $\checkmark$ & Oxpress delivery and delivery order to the \\
\hline$\checkmark$ & & delivery area \\
\hline$\checkmark$ & $\checkmark$ & Pick up \\
\hline$\checkmark$ & $\checkmark$ & Inspection \\
\hline$\checkmark$ & & Scan confirmation order \\
\hline$\checkmark$ & $\checkmark$ & Bale \\
\hline$\checkmark$ & $\checkmark$ & Doods placed in the delivery area \\
\hline$\checkmark$ & & On the train scan \\
\hline & & Get off the scan \\
\hline$\checkmark$ & $\checkmark$ & Distribution \\
\hline$\checkmark$ & $\checkmark$ & Receipt \\
\hline$\checkmark$ & $\checkmark$ & Return and follow-up \\
\hline$\checkmark$ & $\checkmark$ & \\
\hline$\checkmark$ & & \\
\hline
\end{tabular}

Through our comparison above we can see that the logistics process of Jing dong than the days of the cat to reduce the delivery orders and delivery orders to be sent to the goods area, inspection, goods placed delivery area, delivery and a series of links, shortening The delivery time, improve the logistics of distribution efficiency, reducing the turnover of goods, greatly improving the level of Jing dong logistics services, an increase of customer satisfaction. So what is the development of Jing dong logistics and what mode of development?

\section{Jing dong logistics development overview}

Jing dong logistics is mainly to take self-built logistics and self-built and third-party outsourcing combined with crowdsourcing logistics, rural agents, colleges and universities agent five models. In the important areas of the country to achieve self-logistics, is located in the remote, low population density of the three or four lines of the city, with third-party logistics company interaction, for O2O's Jing dong home is more use of public logistics such social resources, In the rural Jing dong is to attract a large number of rural agents, for the campus is the implementation of university agency model.

\subsection{Self-built logistics}

As early as 2007 Jing dong has opened a self-built logistics of the screen, Jing dong logistics so far can be divided into three networks, the first network is the most common B2C network, that is, with the integration of B2C mode. The second network is a large home appliances as the core of the large distribution warehouse, the third network is in 2016 began preparations for the construction of fresh frozen freezer with integrated network, after completion, Jing dong Mall will become the world's only Three with the integration of the network of e - commerce companies. Jing dong has also set up a wholly owned subsidiary of Shanghai and Guangzhou, North China, East China and South China three points into a line, so that most of the country are covered in Jing dong 
logistics and distribution network under the same time continue to strengthen and enrich the company's technical strength, Improve and perfect after-sales service, logistics and distribution and marketing, and other aspects of the hardware and software facilities and service conditions. Jing dong set up to Beijing, Shanghai, Guangzhou and Chengdu, Shenyang, Xi'an as the center of the six logistics platform, in order to provide users with more efficient delivery services to further deepen and expand the company's business space. October 10, Jing dong Asia on the 1st project put into use, is the largest and most advanced one of the logistics business center, Jing dong logistics is moving toward the goal of more and more faster forward.

\subsection{Self-built logistics and third-party logistics combined}

Through the combination of self-built logistics and third-party logistics, Jing dong business has been developed to the secondary and tertiary cities, if every secondary city in the country to establish their own logistics and distribution center, huge investment, and business volume is not enough to maintain the logistics center the operation. Therefore, Jing dong to take with the local third-party logistics company to complete the distribution. In addition, Jing dong also cooperation with manufacturers, because the manufacturers in their own cities have their own after-sales service outlets, have their own logistics and distribution partners or their own logistics and distribution center. Jing dong logistics staff is more commitment to the last mile of the task, as long as the master of the last mile, Jing dong will not only guarantee the speed and efficiency of logistics and can ensure the rapid return of funds.

\subsection{Crowdsourcing logistics}

"Jing dong crowdsourcing" is the "Jing dong home" business extension and expansion, the effective use of social capacity, service more consumers. At present, because $\mathrm{O} 2 \mathrm{O}$ business itself has a timeliness characteristics, to promote business providers through continuous innovation to enhance the rapid delivery experience. When the business volume gradually increase or steep, with the social platform to complete the distribution of power is particularly important. Jing dong crowdsourcing is the introduction of Jing dong a new, social courier service. Everyone in the free time, no matter where they are, can send delivery, earn outside the block, is a new life experience. Jing dong crowdsourcing can help people earn the same time in the body to exercise, to achieve a rich and wonderful life has a wonderful life, as of 2016, the package has already owned 500,000 part-time staff part-time employees.

\section{Jing dong self-built logistics model analysis}

\subsection{Advantage}

(1) Logistics and distribution speed, more secure funds

As the domestic logistics started late, to find a service, speed, cost of the three to achieve a balance of the courier company is very rare, Jing dong Mall through self-built logistics distribution, to bring timely and convenient customer service to ensure the quality of service The Jing dong Mall to implement the "211 limited time" service, fully embodies the self-built logistics of the timeliness and efficiency. Jing dong Mall customers can choose cash on delivery, you can also choose to use credit card (delivery staff comes with POS machine), or even check, cash to settle. Jing dong Mall self-built logistics and distribution system, the distribution staff are their own employees, the distribution staff will receive the payment to the site to pay, cash on delivery cash settlement can fully guarantee the safe and reliable payment, effectively avoid the third party Business in the settlement of funds in the existence of various problems.

(2) Jing dong can effectively control the entire process

Jing dong self-built logistics, can effectively control the entire logistics system of the whole process of operation, to master the logistics aspects of the situation, can be shipped, circulation to 
the sale and other aspects of monitoring, to provide consumers with real-time query, cargo tracking and other services, and Able to promptly on any part of the problems that make a quick response. At the same time Jing dong Mall to quickly access the entire supply chain information flow, according to the dynamics of the market to adjust their own business strategy.

(3) To improve corporate brand value

Jing dong through self-logistics model, efficient logistics and distribution and caring after-sales service, so that customers feel the affinity of the enterprise, in the minds of consumers establish a good corporate image. A good corporate image can drive consumers willing to be familiar with the business, understand the product, enhancing the corporate brand value.

\subsection{Disadvantages}

(1) Investment is too large to increase the risk

Self-distribution system is not low cost, which means that companies must make a larger investment to carry out the completion of the distribution team. And only when the Jing dong in a city's daily orders to reach more than 10,000, to buy land to build logistics center is considered cost-effective. On the other hand, if the lease in a city existing warehouse, the daily order volume should reach more than 5,000 to be considered cost-effective. In this case, the enterprise is too large investment, which means that accompanied by greater risk.

(2) Management of the workforce problem

With the gradual development and improvement of self-logistics system, with the staff team is also constantly growing. A huge national distribution network is bound to need a large staff, as of December 31, 2015, Jing dong total staff of nearly 11 million people, and in 2016, Jing dong will also increase the 40,000 full-time employees, the total number of employees will be more than 15 Million. At the same time, there is 500,000 part-time logistics staff, as well as Jing dong Mall has more than 170,000 villages in China have their own villager agents, so Jing dong has more than 700,000 part-time employees. I believe that in 2016, Jing dong part-time staff will exceed 1 million. Jing dong can effectively manage such a large staff, e-commerce and its own logistics system to achieve efficient operation, it is everyone's expectations.

(3) A single logistics model, logistics, high operating costs

As only for the Jing dong business to provide delivery services, Jing dong's logistics company currently formed a "distribution center - the customer" of the single form of distribution, the formation of a large number of empty behavior, the utilization of logistics resources can only be maintained at $50 \%-60 \%$, logistics efficiency is low, high logistics costs. And ordinary courier logistics services companies are two-way logistics and distribution model, in order to achieve lower operating costs, access to high profits. Jing dong Mall self-built logistics aims to directly control the logistics links to improve service capabilities and the formation of the core strengths of enterprises, thus the rapid occupation of the market, however, due to Jing dong non-professional service system and single-line logistics operation model makes light assets known The burden of business logistics assets is becoming more and more important.

\section{Conclusion}

This article is found in recent years, Jing dong sales continued rapid growth, and Jing dong will finance most of the funds invested in the construction of logistics, each enterprise to make the appropriate decision-making have their own internal reasons, its rapid growth is whether with it is wantonly logistics construction. This article through the first Jing dong and Lynx, Amazon, Dang dang, Su ning several of today's first-class electric business enterprises to conduct horizontal comparative analysis, analysis of Jing dong in customer satisfaction above the other than the 
electricity business enterprises. And then the vertical analysis of the entire online shopping process in the end which part of the Jing dong to attract a large number of customers, through the use of peak finalist we found that the high level of logistics services is the most important reason to attract customers, coupled with the previous horizontal comparison Found that Jing dong logistics services is indeed significantly better than other enterprises. So we can conclude that the rapid growth of sales in Jing dong year after year with its logistics services continue to enhance the logistics network is closely related to the continuous expansion, we believe that the power of Jing dong logistics will be with its logistics network extension in the future competition The evolution of Jing dong become an important competitive advantage may even become the core competitive advantage, let us wait and see.

\section{References}

[1] Bin Hu. China's third-party logistics development model research [J]. Jiangsu traffic engineering, 2002 (6) .

[2] Yanqing Zhu. Jing dong Mall logistics distribution model [J]. Ping Xiang higher specialist Journal of School, 2012 (2) .

[3] Xin Li. Shanxi Province, the development of the fourth party logistics [D]. Shanxi: Shanxi Finance University, 2008.

[4] Yu Zhao. The fourth party logistics problem [J] . Jilin Province economic management cadres Journal of Academic Journal, 2009 (1) . 